\title{
Development and Validation of an Enzyme Linked Immunosorbent Assay for Fluoroquinolones in Animal Feeds
}

\author{
Ramato Ashu Tufa ${ }^{*}$, Daniel G. Pinacho ${ }^{\dagger \dagger}$, Núria Pascual ${ }^{\dagger}$, Mercè Granados ${ }^{*}$, Ramon \\ Companyó $^{* \S}$, M. Pilar Marco ${ }^{\dagger}$ \\ *Department of Analytical Chemistry, Faculty of Chemistry, University of Barcelona, \\ Martí i Franquès 1-11, 08028 Barcelona, Spain. \\ ${ }^{\dagger}$ Nanobiotechnology for Diagnostics Group (Nb4D), Department of Chemical and \\ Biomolecular Nanotechnology. IQAC-CSIC. CIBER of Bioengineering, Biomaterials \\ and Nanomedicine, Jordi Girona 18-26, 08034 Barcelona, Spain
}

$\S$ This work is dedicated to the memory of Dr. Ramon Companyó.

\section{${ }^{\ddagger}$ Author for Correspondence}

Daniel G. Pinacho

Nanobiotechnology for Diagnostics Group (Nb4D)

, IQAC-CSIC \& CIBER de Bioingeniería, Biotemateriales y Nanomedicina

c/ Jordi Girona 18-26, 08034 Barcelona

Spain

Phone: 934006100

FAX: 932045904

E-mail: daniel.gonzalez@iqac.csic.es 


\section{ABSTRACT}

An enzyme-linked immunosorbent assay (ELISA) for analysis of fluoroquinolones residues in animal feeds has been developed and validated according to Commission Decision 2002/657/EC criteria. Initially, direct and indirect competitive ELISA formats were compared for one fluoroquinolone polyclonal antibody (As172) and two monoclonal antibodies (FQ8 and FQ10), in order to find the best combination in terms of simplicity, reduction of matrix effect and sensitivity. The optimal methodology was identified as direct ELISA format using polyclonal antibody As172, able to avoid the matrix effect by only 10 -fold dilution of feed samples. Following the optimized ELISA protocol, the half-maximal inhibitory concentration $\left(\mathrm{IC}_{50}\right)$ and limit of detection (LOD) for enrofloxacin was determined to be $15.2 \mathrm{ng} . \mathrm{g}^{-1}$ and $1.3 \mathrm{ng} . \mathrm{g}^{-1}$, respectively. Decision limit $\left(\mathrm{CC}_{\alpha}\right)$ obtained was $10 \mathrm{ng} \cdot \mathrm{g}^{-1}$ and detection capability $\left(\mathrm{CC}_{\beta}\right)$ was $20 \mathrm{ng} \cdot \mathrm{g}^{-1}$. Significant cross-reactivity values (> $42 \%$ ) were obtained for eight fluoroquinolones by the optimized ELISA method. Moreover, comparison of results from ELISA to that of liquid chromatography with fluorescence detection (LC-Fl) showed good correlation. In general, the developed ELISA allows a rapid, sensitive, and low-cost screening analysis of fluoroquinolone residues in animal feeds.

Keywords: ELISA; Quinolones; Screening method; Feed analysis; Method validation. 


\section{Introduction}

Quinolones are synthetic antimicrobials widely used in human and veterinary medicine (Greene \& Budsberg, 1993; Suh \& Lorber, 1995). Quinolones have a general structure consisting of a 1-substituted-1, 4-dihydro-4-oxopyridine-3-carboxylic moiety combined with an aromatic or heteroaromatic ring. Fluoroquinolones are derived from nalidixic acid by adding 6-fluoro and 7-piperazinyl groups, which enhances their antibacterial action and makes them more effective against gram-negative bacteria and some gram-positive bacteria compared to previously developed quinolones (HernándezArteseros, Barbosa, Compañó, \& Prat, 2002).

In the European Union (EU), in veterinary practices, fluoroquinolones can only be introduced in feedstuffs for therapeutic or prophylactic purposes, under veterinary prescription (Kools, Moltmann, \& Knacker, 2008). However, the use of antimicrobials, other than coccidiostats and histomonostats, as growth promoters is banned in EU ("Regulation (EC) No 1831/2003 on Additives for Use in Animal Nutrition," 2003).

On the other hand, fluoroquinolones can also get unintentionally in feeds, as a result of cross contamination, a phenomenon where by feeds are contaminated during production, usually in the low mg. $\mathrm{kg}^{-1}$ range or below. The unknown exposure of nontarget animal species to contaminated feeds may lead to the occurrence of traces of residues of antimicrobials in foods of animal origin, which may have a potential risk to humans like spreading of antimicrobial resistance (Wassenaar, 2005) or allergies in hypersensitive individuals. In this context, reliable analytical methods for the effective control of fluoroquinolones in feeds are required. 
LC based methods are well suited for confirmatory analysis, especially with mass spectrometry detection (Bogialli, D’Ascenzo, Di Corcia, Laganà, \& Nicolardi, 2008; Jiménez, Rubies, Centrich, Companyó, \& Guiteras, 2011; Zafra-Gómez, Garballo, Ballesteros, Navalón, \& García-Ayuso, 2008), but are expensive, time consuming, and often require complicated sample preparation. Thus, laboratories which manage a large amount of samples need simple and sensitive screening methods with a broad range of detectability to detect non-compliant samples and thus to decrease the number of samples requiring further confirmatory analysis. In addition feed mills also need simple and reliable methods to control the production batches. In this sense, the approach based on enzyme-linked immunosorbent assays (ELISA) appears highly convenient

Few screening methodologies based on ELISAs have been reported for fluoroquinolones in food matrices (Huet, et al., 2006; Jinqing, Haitang, \& Ziliang, 2011; Sheng, Li, Xu, Yuan, \& Wang, 2011; Tittlemier, et al., 2008; Wang, et al., 2007). Dualcolorimetric ELISA developed for full-fat milk samples based on immunoreagents specifically allowed a sensitive determination of fluoroquinolones with a detection limit of $2.4 \mathrm{ng} \cdot \mathrm{mL}^{-1}$ (Jiang, et al., 2013). However, ELISA assays for the determination of fluroquinolones in animal feeds are limited; commercial ELISA kits for determination of fluoroquinolones in feed samples have been tested (Scortichini, Annunziata, Di Girolamo, Buratti, \& Galarini, 2009a). Most of the commercially available kits are based on indirect ELISA format developed for specific analytes, and only few allow the detection of a broad range of compounds, and samples considered having complex matrices. Moreover, sample treatment steps are tedious in some cases, so simple and sensitive methods are required. 
The main objective of this work was to develop a rapid, simple and sensitive ELISA method for the analysis of 10 fluoroquinolones in feed samples. The new methodology is based on immunoreagents specifically developed to detect a wide range of congeners of fluoroquinolones. Two monoclonal antibodies and one polyclonal antiserum were tested in both direct and indirect ELISA formats to identify the most suitable approach. Optimization of the ELISA method was performed in terms of simplicity, reduction of matrix effect and sensitivity.

\section{Materials and methods}

\subsection{Chemicals and immunoreagents}

Norfloxacin, sarafloxacin, danofloxacin, oxolinic acid, flumequine, difloxacin, enrofloxacin, ofloxacin and marbofloxacin were purchased from Fluka (Buchs, Switzerland). Ciprofloxacin was kindly provided by UQUIFA S.A (Lliça de Vall, Spain). Sulfadiazine, amoxicillin, Penicillin G potassium salt, neomycin sulfate, tetracycline-hydrogen chloride, doxycycline, chloramphenicol, tylosin and robenidine were acquired from Aldrich Chemical Co. (Milwaukee, WI). Sulfuric acid $\left(\mathrm{H}_{2} \mathrm{SO}_{4}\right.$, 98\%) and hydrochloric acid $(\mathrm{HCl}, 37 \%)$ were obtained from Merck (Darmstadt, Germany). Dimethyl sulfoxide, hydrogen peroxide (30\%) and 3, 3', 5, 5'tetramethylbenzidine (TMB) were purchased from Fluka (Buchs, Switzerland). Acetonitrile (ACN, HPLC gradient grade) was obtained from Panreac Quimica (Barcelona, Spain). Anti-Rabbit IgG (whole molecule) and peroxidase antibody produced in goat were provided by Sigma Chemical Co. (St. Louis, MO). Horseradish peroxidase (type IV-A, activity of about 100 units per $\mathrm{mg}$ of solid) used for the production of enzyme tracer was purchased from Sigma-Aldrich. Ultrapure water (Milli-Q, Millipore, Molsheim, France) used was $18.2 \mathrm{~m} \Omega . \mathrm{cm}^{-1}$ in resistivity. The 
preparation of the fluoroquinolone haptenized protein conjugates (PrEDA-BSA), monoclonal antibodies (FQ8, FQ10), antiserum (As172) and enzyme tracer (HRP-CCEDA) is described elsewhere (M. P. Marco, F. Sanchez-Baeza, \& Pinacho, Haptenos e inmunoreactivos y su uso en la obtención de anticuerpos de familia e inmunoensayos para quinolonas, 2010; Pinacho, Sánchez-Baeza, \& Marco, 2012). All immunoreagents were stored at $-20{ }^{\circ} \mathrm{C}$. Working aliquots were kept at $4{ }^{\circ} \mathrm{C}$ and aliquots of enzyme tracer solutions were defrozen 1 week before use.

The coating buffer ( $\mathrm{pH} 9.6$ ) was composed of $0.015 \mathrm{M}$ of $\mathrm{Na}_{2} \mathrm{CO}_{3}$ and $0.035 \mathrm{M}$ of $\mathrm{NaHCO}_{3}$ in Milli-Q water. The phosphate-buffered saline solution (PBS) with $\mathrm{pH} 7.5$ was $0.02 \mathrm{M} \mathrm{KH}_{2} \mathrm{PO}_{4}$ and $0.08 \mathrm{M} \mathrm{Na}_{2} \mathrm{HPO}_{4}$ in $0.8 \%$ saline solution $(0.137 \mathrm{M} \mathrm{NaCl}$ and 2.7 M KCl). PBST was PBS with 0.05\% Tween 20. A solution of PBST-Ca (pH 7.5) was $0.01 \mathrm{M}$ phosphate buffer and $2 \mathrm{mM}$ of $\mathrm{CaCl}_{2}$ in a $1.6 \%$ saline solution containing $0.1 \%$ Tween 20 . The citrate buffer was $0.04 \mathrm{M}$ solution of sodium citrate adjusted to $\mathrm{pH}$ 5.5 with $\mathrm{HCl}$. The substrate solution contained $0.01 \% \mathrm{TMB}$ and $0.004 \% \mathrm{H}_{2} \mathrm{O}_{2}$ in citrate buffer. Buffer solutions were prepared every week and stored at $4{ }^{\circ} \mathrm{C}$.

\subsection{Instrumentation and apparatus}

The $\mathrm{pH}$ and conductivity of buffers and solutions were measured with 540 GLP pH meter and LF 340 conductimeter (WTW, Weilheim, Germany), respectively. Polystyrene microtiter plates were obtained from Nunc (Maxisorp, Roskilde, Denmark). A Heidolph Titramax 1000 vibrating platform shaker (Brinkmann Instruments, Westbury, NY, USA) was used to shake the microplates. Washing step was carried out using an automatic 96-well plate washer (ELx405, BioTek, Winooski, VT). SpectramaxPlus (Molecular Devices, Sunnyvale, CA, USA) was used to measure absorbances at $450 \mathrm{~nm}$. Data acquisition was performed with SoftmaxPro version 4.7 
(Molecular Devices) and the analysis of competitive curves with a four parameter logistic equation was done by GraphPad Prism version 4 (GraphPad Software, San Diego, CA, USA). Unless otherwise indicated, data presented correspond to an average of at least two replicates.

HPLC analysis was performed with a Shimadzu LC system consisting of LC10ADVP pumps, a DGU-14A degasser, and FCV-10AL quaternary valve (Shimadzu, China), SIL 10ADVP auto sampler (Shimadzu, USA) and RF-10AXL fluorescence detector (Shimadzu, Japan). The system was controlled via a CBM-20A controller (Shimadzu, USA). A Kinetex C18 (Phenomenex, $150 \times 4.6 \mathrm{~mm}, 2.6 \mu \mathrm{m}$ ) column equipped with the corresponding guard cartridge $(4 \times 2 \mathrm{~mm})$ was employed.

\subsection{Animal Feeds}

Feed samples (pig, cow, piglet, hen, chicken) were provided by the Catalan Association of Feed Manufacturers (ASFAC) and Laboratori Agroalimentari de la Generalitat de Catalunya (LAGC). Feed samples were contained in polyvinylchloride (PVC) flasks and stored at $4{ }^{\circ} \mathrm{C}$. Samples in the form of pellets were ground to a fine powder with a domestic mill. Blank feed samples were analysed by LC-MS/MS (Chico, et al., 2008) and found free of fluroquinolones.

For recovery studies, some feed samples were spiked at three different levels $(5$, $50,500 \mu \mathrm{g} \cdot \mathrm{g}^{-1}$ ) with enrofloxacin following a procedure described elsewhere (Jiménez, Companyó, \& Guiteras, 2009).

\subsection{Extraction offeeds}

Extraction was performed by adding $5 \mathrm{~mL}$ of $0.05 \mathrm{M} \mathrm{HCl}$ and $5 \mathrm{~mL}$ of $\mathrm{ACN}$ to 50 $\mathrm{mL}$ centrifuge tubes containing $1 \mathrm{~g}$ of feed samples according to the procedure proposed 
by Borràs et al (Borràs, Ríos-Kristjánsson, Companyó, \& Prat, 2012). Briefly, the aqueous solution was added first to moisten the dry feed samples and improve extraction efficiency. The mixture was then shaken manually for $2 \mathrm{~min}$, and then 1.1 $\mathrm{mL}$ of $0.1 \mathrm{M}$ PBS was added to the extraction mixture and centrifuged at $3500 \mathrm{~g}$ for 10 min. The extracts were 10-fold diluted before ELISA analysis.

For LC analysis, the same extraction procedure was applied, but no addition of PBS to the extraction mixture was performed.

\subsection{Selection of immunoreagents concentrations}

Two dimensional checkerboard titration experiments were performed to select the optimal concentrations of immunoreagents to be employed in both direct and indirect ELISA formats. For the direct format, measurements were obtained from the binding of enzyme tracer at several concentrations $\left(2 \mathrm{ng} \cdot \mathrm{mL}^{-1}\right.$ to $2 \mu \mathrm{g} \cdot \mathrm{mL}^{-1}, 100 \mu \mathrm{L} /$ well $)$ to a plate coated with antiserum As172 at different dilutions (1/1000 to 1/64000 and zero, 100 $\mu \mathrm{L} /$ well) or with monoclonal antibodies FQ8 and FQ10 at several concentrations (2 ng. $\mathrm{mL}^{-1}$ to $2 \mu \mathrm{g} \cdot \mathrm{mL}^{-1}$ and zero, $100 \mu \mathrm{L} /$ well). In the indirect format, the test was performed by measuring the binding of serial dilutions (1/1000 to $1 / 64000$ and zero, $100 \mu \mathrm{L} /$ well) of antiserum As172 or monoclonal antibodies FQ8 and FQ10 at several concentrations $\left(2 \mu \mathrm{g} \cdot \mathrm{mL}^{-1}\right.$ to $2 \mathrm{ng} \cdot \mathrm{mL}^{-1}$ and zero, $100 \mu \mathrm{L} /$ well $)$ to wells coated with different concentrations of conjugates $\left(2 \mu \mathrm{g} \cdot \mathrm{mL}^{-1}\right.$ to $2 \mathrm{ng} \cdot \mathrm{mL}^{-1}$ and zero, $100 \mu \mathrm{L} /$ well $)$. The optimal concentrations of immunoreagents were chosen by considering a compromise between the enhancement of sensitivity and the reduction of the signal when diluting the immunoreagents. Concentrations of coating antigens and antiserum As172 or FQ8 and FQ10 monoclonal antibodies that produce 0.7-1 units of absorbance were considered as optimal (M.-P. Marco, S. Gee, \& Hammock, 1995). 


\subsection{Optimal direct competitive ELISA}

The coating step was carried out by adding (100 $\mu \mathrm{L} /$ well $)$ solution of As172 (20,000 fold diluted in coating buffer) to the microplates. The plates were covered with adhesive sealers and incubated at room temperature for 3.5 hours. After that, the plates were washed 4 times with $10 \mathrm{mM}$ PBST solution $(300 \mu \mathrm{L} /$ well). The competition step was performed by adding $50 \mu \mathrm{L}$ standard solutions of fluoroquinolones (from 10, 000 to $0.01 \mathrm{nM}$ in PBS) or feed extracts (diluted 10 fold in PBS) and $50 \mu \mathrm{L}$ of enzyme tracer solution $\left(1 \mu \mathrm{g} \cdot \mathrm{mL}^{-1}\right.$ in PBST-Ca) in to each well. The microplates were further incubated for $30 \mathrm{~min}$ at room temperature with agitation. After washing the plates following the previous procedure, $100 \mu \mathrm{L}$ of the substrate solution was added into each well. Finally, the color development was stopped after $30 \mathrm{~min}$ at room temperature, with $2 \mathrm{M} \mathrm{H}_{2} \mathrm{SO}_{4}(50 \mu \mathrm{L} /$ well $)$. The absorbances were read at $450 \mathrm{~nm}$. The standard curves were fitted to a four parameter equation according to the following formula:

$$
Y=\frac{(A-B)}{\left[1-\left(\frac{x}{C}\right)^{D}\right]}+B
$$

Where $A$ is the maximal absorbance, $B$ is the minimum absorbance, $C$ is the concentration producing $50 \%$ of the maximal absorbance $\left(\mathrm{IC}_{50}\right)$, and $D$ is the slope at the inflection point of the sigmoid curve.

\subsection{Matrix Effect Studies.}

Standard curves obtained in feed extracts were compared with standard curves prepared in PBS to assess the matrix effect. Feed extracts were diluted at different levels (2-20 fold) to identify the optimal dilution limit that minimizes matrix effect. 


\subsection{LC analysis}

The LC-FL method used was developed and validated previously (Borràs, et al., 2012). The mobile phase was composed of $0.01 \mathrm{M}$ oxalic acid (pH 4) and ACN. The flow rate was set to $1.2 \mathrm{~mL} \cdot \mathrm{min}^{-1}$. The elution profile starts with isocratic elution with $12 \% \mathrm{ACN}$ for 8 min followed by a gradient elution from $12 \%$ to $30 \%$ of $\mathrm{ACN}$ in 4 min, set back to $12 \% \mathrm{ACN}$ in $2 \mathrm{~min}$ and finally $2 \mathrm{~min}$ for equilibration. The fluorimetric detector was set at excitation/emission wavelengths of $280 / 450 \mathrm{~nm}$. The injection volume was $30 \mu \mathrm{L}$. Feed extracts were diluted 5 fold in mobile phase, filtered through $0.45 \mu \mathrm{m}$ nylon membrane and injected into the chromatographic system.

\subsection{Validation Studies}

The immunoassay method was validated according to the Commission Decision 2002/657/EC criteria ("Commission Decision (EC) No. 657/2002 Concerning the Performance of Analytical Methods and the Interpretation of Results," 2002). Parameters like precision, accuracy, limit of detection (LOD), decision limit $\left(C C_{\alpha}\right)$, detection capability $\left(C C_{\beta}\right)$, specificity, selectivity and ruggedness was determined.

Blank feed extracts were spiked with enrofloxacin at six different concentrations $\left(10,22,45,90,135,180 \mu \mathrm{g} . \mathrm{L}^{-1}\right)$ to assess the precision and trueness of the method. Moreover, blank feed samples were spiked at three different concentrations (5, 50 and $\left.500 \mu \mathrm{g} \cdot \mathrm{g}^{-1}\right)$ with enrofloxacin to evaluate the recovery of the method.

For the assessment of specificity of the assay, compounds structurally related to enrofloxacin as well as other antimicrobials were tested to evaluate the cross reactivity in feed samples. Stock solutions $(10 \mathrm{mM})$ were prepared in sodium hydroxide $50 \mathrm{mM}$ for different fluoroquinolones and other antibiotics. Diluted standard solutions were 
prepared for each compound in PBS and measured with the ELISA. The fluoroquinolones tested were ciprofloxacin, marbofloxacin, danofloxacin, difloxacin, norfloxacin, ofloxacin, sarafloxacin, flumequine and oxolinic acid. The fluoroquinolone group specificity was evaluated by determining the cross reactivity of antibiotics from other classes (sulfonamides, macrolides, tetracyclines, coccidiostats, aminoglycosides, $\beta$-lactams and chloramphenicol). The cross reactivity $(C R)$ values were calculated according to the equation:

$$
C R=\left(\frac{\mathrm{IC}_{50} \text { of enrofloxacin }}{\mathrm{IC}_{50} \text { of tested compound }}\right) \times 100
$$

The limit of detection (LOD) was calculated as the concentration resulting in $90 \%$ of the maximum signal.

For the determination of $C C_{\alpha}$ and $C C_{\beta} 20$ blank samples were analysed in repetitive experiments. The two parameters were calculated using a method based on the variability in blank signals (Galarini, Buratti, Fioroni, Contiero, \& Lega, 2011; Jiménez, Adrian, Guiteras, Marco, \& Companyó, 2010).

Minor variations in optimal values of some parameters thought to affect the immunoassay were introduced to evaluate the robustness of the method. Seven variables were selected and experiments were planned based on the Youden factorial design (Scortichini, et al., 2009a; Vander Heyden, Nijhuis, Smeyers-Verbeke, Vandeginste, \& Massart, 2001; Youden \& Steiner, 1975). The effect of each variable was estimated by subtracting the mean result obtained with the variable at higher level from the mean result obtained at lower level. The influence of each factor was evaluated by using a two tailed $t$-test (Vander Heyden, et al., 2001). 
The absence of matrix effect after proper dilution of extracts, and hence the applicability to different feeds, was shown by applying the optimized ELISA method to chicken, hen, cow, and piglet feeds. Besides, blank feed samples spiked at three different concentrations $\left(5,50,500 \mu \mathrm{g} \cdot \mathrm{g}^{-1}\right)$ with enrofloxacin were analysed with the ELISA method and a confirmatory LC-FL method. The correlation between the results from ELISA and LC-FL was used to demonstrate the reliability of the ELISA method as a screening and semi-quantitative analytical tool.

\section{Results and discussions}

\subsection{Immunoassay evaluation and selection of ELISA}

The selection of the immunoreagents and final format was performed based on sensitivity, reduction of matrix effect and selectivity of the assays. Enrofloxacin is the most widely applied fluroquinolone in veterinary and hence this compound was selected as a representative of other fluoroquinoles in preliminary studies. Polyclonal antiserum As172 and monoclonal antibodies FQ8 and FQ10 were employed in both direct and indirect ELISA formats, to select the conditions for the fluoroquinolones. A representative pig feed was used to run competitive ELISA for the assessment assay. First, proper concentrations of immunoreagents were chosen using a checkerboard titration experiments. For indirect ELISA format, polyclonal As172 was used at 1: 32,000 dilution while monoclonals FQ8 and FQ10 were used at 1 and $0.5 \mu \mathrm{g} \cdot \mathrm{mL}^{-1}$, respectively. In direct ELISA format, As172 was used at 1: 20,000 dilution while FQ8 and FQ10 were used at of 0.5 and $1 \mu \mathrm{g} \cdot \mathrm{mL}^{-1}$, respectively.

Regarding sensitivity, the levels of $\mathrm{IC}_{50}$ and LOD were initially determined for all antibodies by direct and indirect format. As shown in Table 1, for As172 and both monoclonal antibodies, the direct format gives lower $\mathrm{IC}_{50}$ and LOD than the indirect 
format. The matrix effect studies were initially performed with pig feed extracts spiked with enrofloxacin at several concentration levels. Results from preliminary studies indicate that the direct ELISA format is less susceptible to the matrix effect than the indirect format, as shown in Figure 1. Thus, for As172 and FQ8, a 10 fold dilution of the pig feed extract was enough to avoid the matrix effect, i.e. the standards in feed extract overlapped with those corresponding to PBS. FQ10 was more affected by the feed matrix, and 25 fold dilutions were required to overcome the matrix effect. Besides, the results obtained from the direct ELISA formats were more reproducible than the indirect ELISA format.

Based on the previous results, further experiments with other feeds were carried out using As172 and FQ8 direct assays. Figure 2 shows standard curves in PBS buffer and standard curves in different feed extracts diluted 10 fold for direct competitive ELISA with As 172 and FQ8. The results pointed out that As172 was less susceptible to the matrix effects than FQ8. Moreover, the cross reactivity studies show that As172 has a higher recognition profile and sensitivity for the tested fluoroquinolones than FQ8 (see Table 2). Hence direct ELISA based on As172 was the optimal choice due to its simplicity, sensitivity and tolerance of the matrix effect.

\subsection{Sample extraction}

The extraction method is highly efficient, with extraction recovery rate above $80 \%$ for the assayed fluoroquinolones. For the ELISA method it is necessary to dilute the extracts with PBS to obtain feed extracts in $10 \mathrm{mM}$ PBS, like the calibration standards. Since the addition of PBS to the extracts after centrifugation resulted in salt precipitation, it was decided to add PBS before centrifugation. In this way clear 
solutions were obtained, ready to be analyzed by the ELISA method. This extraction method is simpler and quicker than other reported methods.

\subsection{ELISA validation studies}

To study the specificity of the assay, compounds which are structurally related to enrofloxacin and compounds from other classes of antibiotics were tested. The $\mathrm{IC}_{50}$, LOD (determined as $\mathrm{IC}_{90}$ ) and the cross-reactivity values in feed for the tested fluoroquinolones are shown in Table 2. A significant cross reactivity was obtained with the tested compounds, except for flumequine and oxolinic acid $(<5 \%)$. Hence, the direct competitive ELISA could potentially be applied for the determination of most of the tested fluoroquinolones. Besides, very low cross reactivity values $(<0.1 \%)$ shows that the antibody doesn't cross react with tested antibiotics from other classes. This shows high group specificity of the developed ELISA method towards fluoroquinolones.

Extracts from five different feeds (cow, pig, piglet, hen and chicken) were spiked with enrofloxacin at six concentrations levels, from $10-180 \mu \mathrm{g} . \mathrm{L}^{-1}$. Figure 3 presents the correlation between the real concentrations in spiked feeds and the ELISA measured concentrations. The slopes and correlation coefficients $\left(\mathrm{R}^{2}\right)$ of the regression lines obtained for the different feeds were between 0.8195-1.086 and 0.96-0.99, respectively, which indicates good accuracy of the developed assay.

Feed samples spiked with enrofloxacin at three different concentration levels were extracted and analysed to evaluate the recovery of the ELISA method. The recovery values were in the range of $75-116 \%$. In addition, the values measured by ELISA were compared with the values obtained by LC-Fl (Table 3). Comparable results were obtained from both methods. 
The precision of the assay was determined based on inter-assay and intra-assay variations in the $\mathrm{IC}_{50}$ and recovery values. The values were expressed as relative standard deviation of the results obtained from repetitive experiments. Intra-assay repeatability based on the variations with-in and between the plates was below $9 \%$ $(n=3)$ while the inter-assay reproducibility was below $21 \%(n=3)$. Intra-day and interday precisions in recovery values of pig feed extracts spiked in the range of $10-360$ $\mu \mathrm{g} . \mathrm{L}^{-1}$ were below $12 \%$ and $23 \%$, respectively. The precision in the recoveries of pig feeds spiked at 5,50 and $500 \mu \mathrm{g} . \mathrm{g}^{-1}$ shows intra-day and inter-day repeatability values below $16 \%$ and $25 \%$, respectively. Moreover, intra-day and inter-day precision varies between $15-20 \%$ for extracts spiked at $C C_{\beta}$ level.

According to the Commission Decision 2002/657/EC, the determination of $C C_{\alpha}$ is not mandatory for screening tests. However, fixing $C C_{\alpha}$ as a discriminating value helps in evaluation of the false compliant rate of a screening method for a banned substance. Thus, it has been determined as discriminating value for in many screening tests (Adrian, et al., 2009; Bovee, Heskamp, Hamers, Hoogenboom, \& Nielen, 2005; Galarini, et al., 2011; Hagren, Peippo, Tuomola, \& Lövgren, 2006; Huet, et al., 2006; Jiménez, et al., 2010; Peippo, Lövgren, \& Tuomola, 2005; Scortichini, et al., 2009a). In this study, $C C_{\alpha}$ and $C C_{\beta}$ were determined from repetitive experiments performed on blank samples as follows: $A_{c c \alpha}=A_{a v}-2.33 s_{b} ; A_{c c \beta}=A_{c c \alpha}-1.64 s_{b}$, where $A_{c c \alpha}, A_{c c \beta}, A_{a v}$ and $s_{b}$ are absorbance at $C C_{\alpha}$, absorbance at $C C_{\beta}$, average absorbance of 20 blank feed extracts and standard deviation of 20 blank feed extracts, respectively. The concentrations are calculated from the absorbance values using enrofloxacin calibration curves. $C C_{\alpha}$ was determined to be $10 \mathrm{ng} . \mathrm{g}^{-1}$ while $C C_{\beta}$ was $20 \mathrm{ng} \cdot \mathrm{g}^{-1}$ in pig feed matrix. The $C C_{\beta}$ obtained here is 50 times lower than the value reported by Scortichini et al. 
(Scortichini, Annunziata, Di Girolamo, Buratti, \& Galarini, 2009b) indicating a powerful sensitivity of the developed method. Once the values of $C C_{\alpha}, C C_{\beta}$ were determined, evaluation of the false compliant and false non-compliant rates was done by analyzing blank feeds. Both $\alpha$ and $\beta$ error should be less than $5 \%$ for a valid screening method as mentioned on Commission Decision 2002/657/EC. In our study, 20 blank feeds and 20 spiked feeds (at $C C_{\beta}$ level) were analysed to verify the absence of false compliant and false non-compliant decisions. Results indicate that the false compliant and false non-compliant rates were zero, as shown in Figure 4.

For robustness study, seven variables (ACN concentration, shaking time, dilution factor, competition time, $\mathrm{pH}$ of buffer, incubation temperature and delay in instrumental reading) were selected for the experimental design based on the Youden approach (Youden \& Steiner, 1975). The effect of the variables was estimated as the differences in results obtained with the variables set at 'high level' and 'low level' and the effects were evaluated with two tailed t-test (Table 4). The level of the tested variables had no significant effects $(\alpha<0.05)$ on the results of the ELISA assay, pointing out that the method is robust against variations of the selected variables in the assayed ranges.

Finally, pig feed samples contaminated with enrofloxacin (samples $S_{\mathrm{e} 1}$ and $S_{\mathrm{e} 2}$ ), danofloxacin (sample $\mathrm{S}_{\mathrm{d}}$ ), sarafloxacin (sample $\mathrm{S}_{\mathrm{s}}$ ) were analyzed by LC and the proposed ELISA method. Samples were obtained from LAGC, the official laboratory for feed analysis in Catalonia (Spain), and from local feed producers. Concentrations of danofloxacin and sarafloxacin obtained by the ELISA method were expressed as equivalents of enrofloxacin considering their cross reactivities (Table 5). Comparable results were obtained from both methods indicating that the proposed method can reliably be applied for the control of contaminated or medicated feeds. 


\section{Conclusion}

The ELISA proposed method, which combines a very simple sample treatment with a direct ELISA based on a polyclonal antiserum As172, can be applied for a throughput screening of fluoroquinolones residues in feed samples and it is well suited for screening large number of samples. Unlike other ELISA assays, no treatment of the sample extract other than dilution was involved, even for complex feeds samples. Thus, only 10 -fold dilution of the final feed extract is required to avoid the matrix effect when using polyclonal antiserum As172 compared to monoclonal ones. Moreover, the relevant cross-reactivity of the assay towards fluoroquinoles indicates higher recognition profile and sensitivity of the polyclonal antiserum As172 in the direct format. This enables accurate and broad range detection for this family of compounds. A detection capability of $20 \mathrm{ng} \cdot \mathrm{g}^{-1}$ for enrofloxacin indicates that the method is very sensitive. All these, in addition to the robustness of the assay, makes this ELISA method very suitable for effective control of cross contamination during feed production or to detect unauthorized use of fluoriquinolones in bad farming practices.

\section{Acknowledgements}

This work has been supported by the Spanish Ministry of Science and Technology (Contract number AGL2008-05578-C05-01). The Nb4D group (formerly Applied Molecular Receptors group, AMRg) is a consolidated research group (Grup de Recerca) of the Generalitat de Catalunya and has support from the Departament d'Universitats, Recerca i Societat de la Informació de la Generalitat de Catalunya (expedient: 2014 SGR 1484). CIBER-BBN is an initiative funded by the VI National R\&D\&I Plan 20082011, Initiative Ingenio 2010, Consolider Program, CIBER Actions and financed by the Instituto de Salud Carlos III with assistance from the European Regional Development 
Fund. R.A. Tufa had a fellowship from Generalitat of Catalonia. We also thank LAGC and ASFAC for providing feed samples.

\section{References}

Adrian, J., Gratacós-Cubarsí, M., Sánchez-Baeza, F., Garcia Regueiro, J.-A., Castellari, M., \& Marco, M. P. (2009). Traceability of sulfonamide antibiotic treatment by immunochemical analysis of farm animal hair samples. Analytical and Bioanalytical Chemistry, 395(4), 1009-1016.

Bogialli, S., D’Ascenzo, G., Di Corcia, A., Laganà, A., \& Nicolardi, S. (2008). A simple and rapid assay based on hot water extraction and liquid chromatography-tandem mass spectrometry for monitoring quinolone residues in bovine milk. Food Chemistry, 108(1), 354-360.

Borràs, S., Ríos-Kristjánsson, J.-G., Companyó, R., \& Prat, M.-D. (2012). Analysis of fluoroquinolones in animal feeds by liquid chromatography with fluorescence detection. Journal of Separation Science, 35(16), 2048-2053.

Bovee, T. F. H., Heskamp, H. H., Hamers, A. R. M., Hoogenboom, R. L. A. P., \& Nielen, M. W. F. (2005). Validation of a rapid yeast estrogen bioassay, based on the expression of green fluorescent protein, for the screening of estrogenic activity in calf urine. Analytica Chimica Acta, 529(1-2), 57-64.

Chico, J., Rúbies, A., Centrich, F., Companyó, R., Prat, M. D., \& Granados, M. (2008). High-throughput multiclass method for antibiotic residue analysis by liquid chromatography-tandem mass spectrometry. Journal of Chromatography A, 1213(2), 189-199. 
Commission Decision (EC) No. 657/2002 Concerning the Performance of Analytical Methods and the Interpretation of Results. (2002). Off. J. Eur. Commun., L221, 8.

Galarini, R., Buratti, R., Fioroni, L., Contiero, L., \& Lega, F. (2011). Development, validation and data quality assurance of screening methods: A case study. Analytica Chimica Acta, 700(1-2), 2-10.

Greene, C., \& Budsberg, S. (1993). Veterinary use of quinolones. In W. J. Hooper DC, editors (Ed.), "Quinolone antimicrobial agents" (2nd ed.). Washington, DC: American Society for Microbiology.

Hagren, V., Peippo, P., Tuomola, M., \& Lövgren, T. (2006). Rapid time-resolved fluoroimmunoassay for the screening of monensin residues in eggs. Analytica Chimica Acta, 557(1-2), 164-168.

Hernández-Arteseros, J. A., Barbosa, J., Compañó, R., \& Prat, M. D. (2002). Analysis of quinolone residues in edible animal products. Journal of Chromatography A, $945(1-2), 1-24$.

Huet, A.-C., Charlier, C., Tittlemier, S. A., Singh, G., Benrejeb, S., \& Delahaut, P. (2006). Simultaneous determination of (fluoro)quinolone antibiotics in kidney, marine products, eggs, and muscle by enzyme-linked immunosorbent assay (ELISA). Journal of Agricultural and Food Chemistry, 54(8), 2822-2827.

Jiang, W., Wang, Z., Beier, R. C., Jiang, H., Wu, Y., \& Shen, J. (2013). Simultaneous determination of 13 fluoroquinolone and 22 sulfonamide residues in milk by a dual-colorimetric enzyme-linked immunosorbent assay. Analytical chemistry, 85(4), 1995-1999.

Jiménez, V., Adrian, J., Guiteras, J., Marco, M.-P., \& Companyó, R. (2010). Validation of an Enzyme-Linked Immunosorbent Assay for Detecting Sulfonamides in 
Feed Resources. Journal of Agricultural and Food Chemistry, 58(13), 75267531.

Jiménez, V., Companyó, R., \& Guiteras, J. (2009). Preparation of quality control materials for the determination of sulfonamides in animal feed. Food Additives \& Contaminants, Part A: Chemistry, Analysis, Control, Exposure \& Risk Assessment, 26(7), 969 - 977.

Jiménez, V., Rubies, A., Centrich, F., Companyó, R., \& Guiteras, J. (2011). Development and validation of a multiclass method for the analysis of antibiotic residues in eggs by liquid chromatography-tandem mass spectrometry. Journal of Chromatography A, 1218(11), 1443-1451.

Jinqing, J., Haitang, Z., \& Ziliang, W. (2011). Multiresidue determination of sarafloxacin, difloxacin, norfloxacin, and pefloxacin in fish using an enzymelinked immunosorbent assay. Procedia Environmental Sciences, 8(0), 301-306.

Kools, S. A. E., Moltmann, J. F., \& Knacker, T. (2008). Estimating the use of veterinary medicines in the European union. Regulatory Toxicology and Pharmacology, $50(1), 59-65$.

M.-P. Marco, S. Gee, \& Hammock, B. D. (1995). Trends Anal. Chem.: Immunochemical techniques for environmental analysis. II. Antibody production and immunoassay development, by M.-P. Marco, S. Gee and B.D. Hammock; vol. 14, No. 8, pp. 415-425. TrAC Trends in Analytical Chemistry, 14(9), 463.

M. P. Marco, F. Sanchez-Baeza, \& Pinacho, D. G. (Haptenos e inmunoreactivos y su uso en la obtención de anticuerpos de familia e inmunoensayos para quinolonas, 2010) OEPM Madrid (Vol. P201031721.). Spain. 
Peippo, P., Lövgren, T., \& Tuomola, M. (2005). Rapid screening of narasin residues in poultry plasma by time-resolved fluoroimmunoassay. Analytica Chimica Acta, 529(1-2), 27-31.

Pinacho, D. G., Sánchez-Baeza, F., \& Marco, M. P. (2012). Molecular Modeling Assisted Hapten Design To Produce Broad Selectivity Antibodies for Fluoroquinolone Antibiotics. Analytical Chemistry, 84(10), 4527-4534.

Regulation (EC) No 1831/2003 on Additives for Use in Animal Nutrition. (2003). Off. J. Eur. Union, L 268, 29.

Scortichini, G., Annunziata, L., Di Girolamo, V., Buratti, R., \& Galarini, R. (2009a). Validation of an enzyme-linked immunosorbent assay screening for quinolones in egg, poultry muscle and feed samples. Analytica Chimica Acta, 637(1-2), 273-278.

Scortichini, G., Annunziata, L., Di Girolamo, V., Buratti, R., \& Galarini, R. (2009b). Validation of an enzyme-linked immunosorbent assay screening for quinolones in egg, poultry muscle and feed samples. Analytica Chimica Acta, 637(1), 273278.

Sheng, W., Li, Y., Xu, X., Yuan, M., \& Wang, S. (2011). Enzyme-linked immunosorbent assay and colloidal gold-based immunochromatographic assay for several (fluoro)quinolones in milk. Microchimica Acta, 173(3), 307-316.

Suh, B., \& Lorber, B. (1995). Quinolones. The Medical Clinics of North America, 79(4), 869-894.

Tittlemier, S., Gélinas, J.-M., Dufresne, G., Haria, M., Querry, J., Cleroux, C., Ménard, C., Delahaut, P., Singh, G., Fischer-Durand, N., \& Godefroy, S. (2008). Development of a direct competitive enzyme-linked immunosorbent assay for 
the detection of fluoroquinolone residues in shrimp. Food Analytical Methods, $1(1), 28-35$.

Vander Heyden, Y., Nijhuis, A., Smeyers-Verbeke, J., Vandeginste, B. G. M., \& Massart, D. L. (2001). Guidance for robustness/ruggedness tests in method validation. Journal of Pharmaceutical and Biomedical Analysis, 24(5-6), 723753.

Wang, Z., Zhu, Y., Ding, S., He, F., Beier, R. C., Li, J., Jiang, H., Feng, C., Wan, Y., Zhang, S., Kai, Z., Yang, X., \& Shen, J. (2007). Development of a monoclonal antibody-based broad-specificity ELISA for fluoroquinolone antibiotics in foods and molecular modeling studies of cross-reactive compounds. Analytical Chemistry, 79(12), 4471-4483.

Wassenaar, T. M. (2005). Use of antimicrobial agents in veterinary medicine and implications for human health. Critical Reviews in Microbiology, 31(3), 155169.

Youden, W. J., \& Steiner, E. H. (1975). Statistical manual of association of official analytical chemists. In (pp. 33- 36, 82- 83). Arlington, VA: Association of Official Analytical Chemists.

Zafra-Gómez, A., Garballo, A., Ballesteros, O., Navalón, A., \& García-Ayuso, L. E. (2008). Simultaneous determination of quinolone antibacterials in bovine milk by liquid chromatography-mass spectrometry. Biomedical Chromatography, 22(11), 1186-1193. 


\section{Figure legends}

Figure 1. Standard curves for enrofloxacin in PBS and in feed extracts diluted at three different levels $(5,10$ and 25 fold). The assay was done following direct ( $a, b$ and $c)$ and indirect (d, e and f) ELISA formats with three different antibodies. M/5, M/10 and M/25 represent 5, 10 and 25 fold dilutions of the feed extracts. A/10 represents 10 fold dilution of the extracting solution. The $\mathrm{pH}$ of the blank feed extracts was adjusted to 7.5 after dilution.

Figure 2. Standard curve for enrofloxacin in PBS and in extracts from three different blank feeds (pig, cow and piglet) diluted 10 fold. The assay was done following direct ELISA format with antibodies As172 (a) and FQ8 (b). The pH of the blank feed extracts was adjusted to 7.5 after dilution.

Figure 3. Accuracy studies with feed extracts spiked at six different concentrations (11, $22,45,90,135,180 \mu \mathrm{g} . \mathrm{L}^{-1}$ ) with enrofloxacin. Each data represents the mean value of three independent experiments with $95 \%$ confidence limit.

Figure 4. Verification of the absence of false compliant and false non-compliant. $C C_{\alpha}$ and $C C_{\beta}$ were determined from the variations in the absorbance of 20 blank feeds. Determinations were made using standard curves obtained from quadruplicate data; Optimal direct format using polyclonal antiserum As172 was used for ELISA measurements. 


\section{TABLES}

Table 1. $\mathrm{IC}_{50}$ and LOD values for enrofloxacin in phosphate buffer solution with direct and indirect ELISA format employing polyclonal antiserum (As172) and monoclonal antibodies (FQ8 or FQ10).

\begin{tabular}{lcccc}
\hline \multirow{2}{*}{ Antibodies } & \multicolumn{3}{c}{ LOD $\left(\mathrm{ng} \cdot \mathrm{mL}_{50}^{-1}\right)^{*}$} \\
\cline { 2 - 5 } & Direct ELISA & Indirect ELISA & Direct ELISA & Indirect ELISA \\
\hline As172 & 10.5 & 78.2 & 0.5 & 8.4 \\
FQ8 & 5.5 & 94.6 & 0.6 & 39.2 \\
FQ10 & 7.7 & 13 & 0.9 & 1.6 \\
\hline
\end{tabular}

*LOD values were estimated as $I C_{90}$ values. 
Table 2. Cross reactivity, $\mathrm{IC}_{50}$ and $\mathrm{LOD}$ values of fluoroquinolones in the pig feed matrix.

\begin{tabular}{|c|c|c|c|c|c|c|}
\hline \multirow[b]{3}{*}{ Enrofloxacin } & \multicolumn{3}{|c|}{ Antiserum As172 } & \multicolumn{3}{|c|}{ Monoclonal antibody FQ8 } \\
\hline & $\begin{array}{c}\mathrm{IC}_{50} \\
\left(\text { ng. } \mathrm{g}^{-1}\right)\end{array}$ & $\begin{array}{c}\text { LOD } \\
\left(\text { ng. } \text { g }^{-1}\right)^{*}\end{array}$ & $\%$ Cross Reactivity & $\begin{array}{c}\mathrm{IC}_{50} \\
\left.\text { (ng. } \mathrm{g}^{-1}\right)\end{array}$ & $\begin{array}{c}\text { LOD } \\
\left(\text { ng. } \text { g }^{-1}\right)^{*}\end{array}$ & $\%$ Cross Reactivity \\
\hline & 15.2 & 1.3 & 100 & 16.3 & 0.8 & 100 \\
\hline Ciprofloxacin & 7.181 & 0.5 & 211.1 & 10.3 & 0.6 & 157.9 \\
\hline Sarafloxacin & 4.259 & 0.04 & 355.9 & 42 & 8.7 & 38.7 \\
\hline Difloxacin & 3.684 & 0.03 & 411.4 & 41 & 4.6 & 39.7 \\
\hline Ofloxacin & 20.9 & 1 & 72.6 & - & - & - \\
\hline Danofloxacin & 35.6 & 0.4 & 42.6 & 33.9 & 3 & 48 \\
\hline Norfloxacin & 7.2 & 0.3 & 210.1 & 32.2 & 2.8 & 50.5 \\
\hline Marbofloxacin & 33.4 & 2.3 & 45.4 & 21.7 & 2.3 & 74.8 \\
\hline Oxolinic Acid & 291.3 & 14.9 & 5.2 & - & - & - \\
\hline Flumequine & 346.7 & 16.1 & 4.4 & 280 & 43.4 & 5.8 \\
\hline
\end{tabular}

*LOD values were estimated as $I C_{90}$ 
Table 3. Comparison of the determinations for different spike levels of pig feed by ELISA and LC methods; ELISA assay was performed in direct format using polyclonal antiserum As172.

\begin{tabular}{ccccc}
\hline $\begin{array}{c}\text { Spike Level, } \\
\mu \mathrm{g} \cdot \mathrm{g}^{-1}\end{array}$ & \multicolumn{2}{c}{ Elisa } & \multicolumn{2}{c}{ HPLC } \\
\cline { 2 - 5 } & $\begin{array}{c}\text { Measured } \\
\text { Value, } \mu \mathrm{g} \cdot \mathrm{g}^{-1}\end{array}$ & \% RSD* & $\begin{array}{c}\text { Measured } \\
\text { Value, } \mu \mathrm{g} \cdot \mathrm{g}^{-1}\end{array}$ & $\%$ RSD** \\
\hline 5 & 3.9 & 15 & 4.2 & 2 \\
50 & 58 & 23 & 44 & 5 \\
500 & 377 & 12 & 430 & 3 \\
\hline
\end{tabular}

*Calculated from three determinations in three different days

**Calculated from the three replicate determinations 
Table 4. Minor variations in the selected variables for robustness study for the optimal direct ELISA format using polyclonal antiserum As172, estimated level of the effect and calculated t-values.

\begin{tabular}{|c|c|c|c|c|c|c|}
\hline Selected variables & Unit & $\begin{array}{c}\text { Optimal } \\
\text { value }\end{array}$ & Higher values & Low values & $\begin{array}{c}\text { \% Difference in } \\
\text { recovery* }\end{array}$ & $\begin{array}{c}\text { Calculated } t \text {-value, } \\
\qquad t_{\exp } * *\end{array}$ \\
\hline ACN Concentration & $\%$ & $50 \%$ & 45 & 55 & 12.8 & 1.18 \\
\hline Shaking time & $\min$ & 1.5 & 1.25 & 1.75 & 18.9 & 1.74 \\
\hline Dilution factor & - & $1: 10$ & $1: 8$ & $1: 12$ & 10.4 & 0.96 \\
\hline Compition time & $\min$ & 30 & 25 & 35 & 18.3 & 1.69 \\
\hline $\mathrm{pH}$ of buffer & - & 7.5 & 7.3 & 7.7 & 6.4 & 0.59 \\
\hline $\begin{array}{l}\text { Incubation } \\
\text { temperature }\end{array}$ & ${ }^{0} \mathrm{C}$ & 25 & 21 & 28 & 17.8 & 1.64 \\
\hline Delay in reading & $\min$ & 6 & 3 & 12 & 3.4 & 0.32 \\
\hline
\end{tabular}

*The recovery values were obtained by analyzing a $5 \mu \mathrm{g} \cdot \mathrm{g}^{-1}$ of pig feed with the designed experiments.

$* * t_{\text {exp }}$ was calculated based on the standard deviations estimated from blank feeds spiked at $C C_{\beta} ; t_{\text {crit }}=2.09$ at $N-1=19, \alpha=0.05$ 
Table 5. Comparison of the determinations of contaminated pig feeds by ELISA and

LC methods; ELISA measurements were done following a direct format using polyclonal antiserum As172.

\begin{tabular}{ccccc}
\hline Sample & \multicolumn{2}{c}{ LC } & \multicolumn{2}{c}{ ELISA } \\
\cline { 2 - 5 } & Measured Value, ng.g & \% RSD* & Measured Value, ng.g & \% RSD $^{-1}$ \\
\hline $\mathrm{S}_{\mathrm{e} 1}$ & 0.2 & 7.1 & 0.4 & 15 \\
$\mathrm{~S}_{\mathrm{e} 2}$ & 4.6 & 8.2 & 5.0 & 12 \\
$\mathrm{~S}_{\mathrm{d}}$ & 14 & 3.0 & 12 & 9 \\
$\mathrm{~S}_{\mathrm{S}}$ & 6.0 & 6.0 & 8.1 & 17 \\
\hline
\end{tabular}

*Calculated from six replicate determinations 
1.
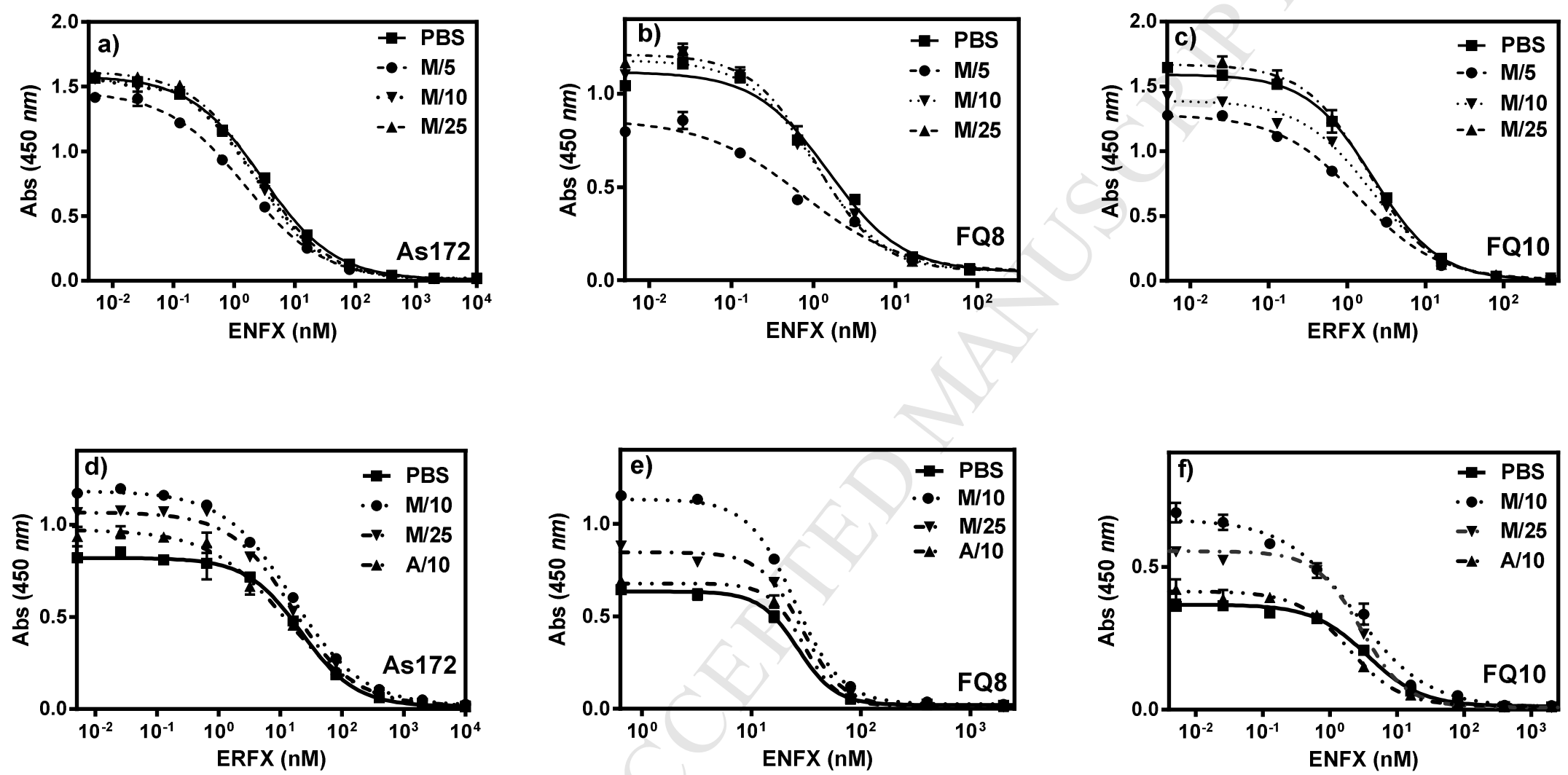
a.

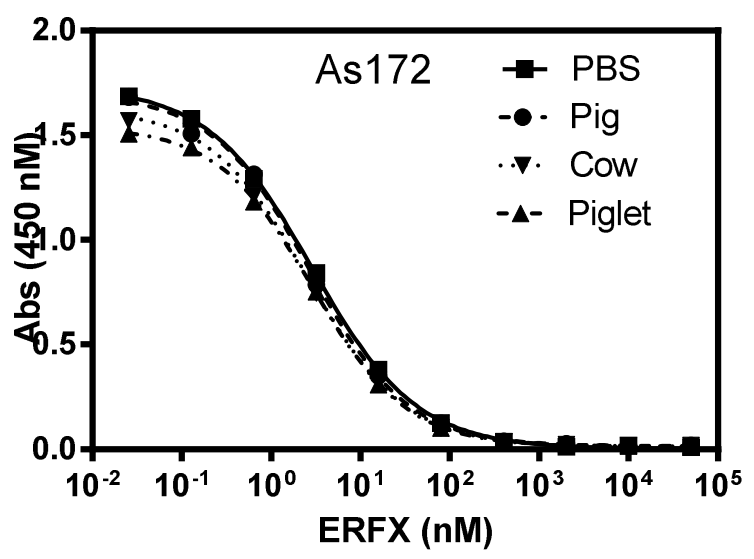

b.

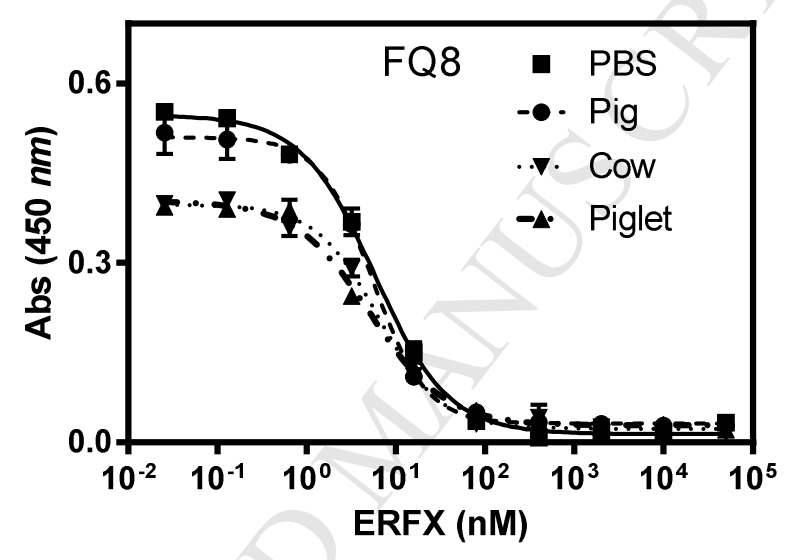


3.

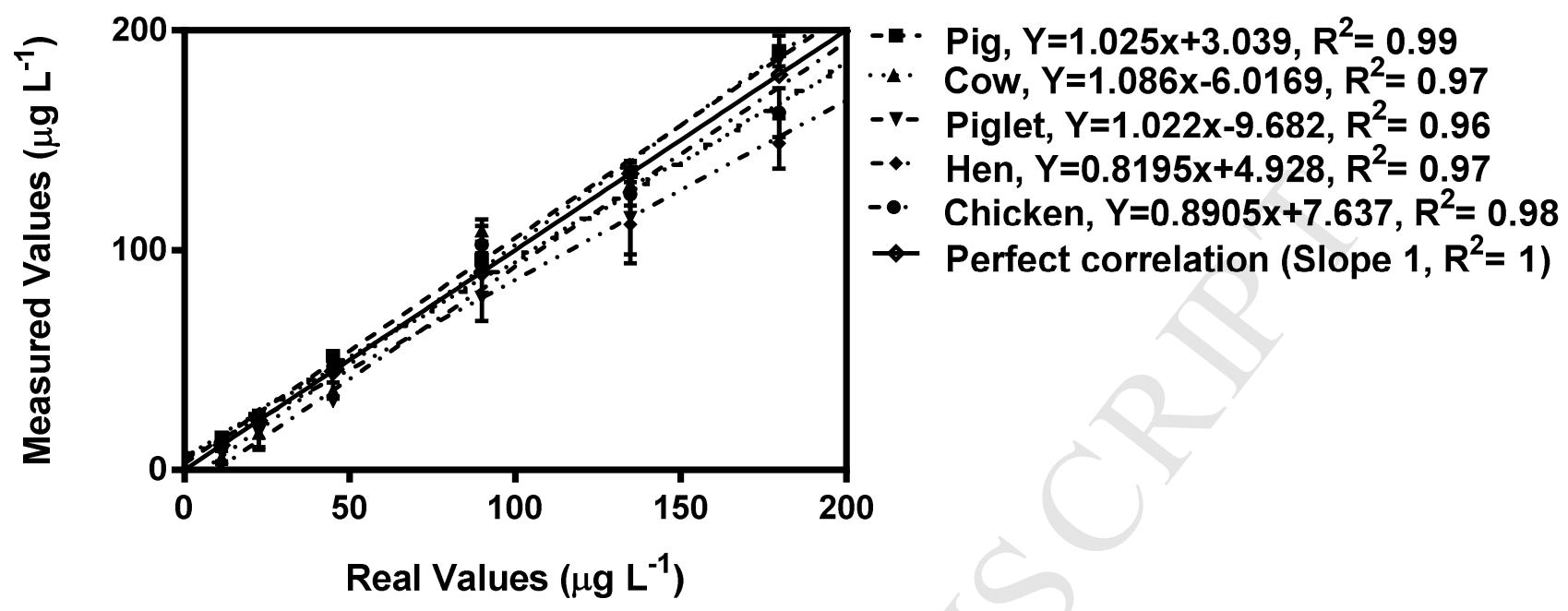


4.

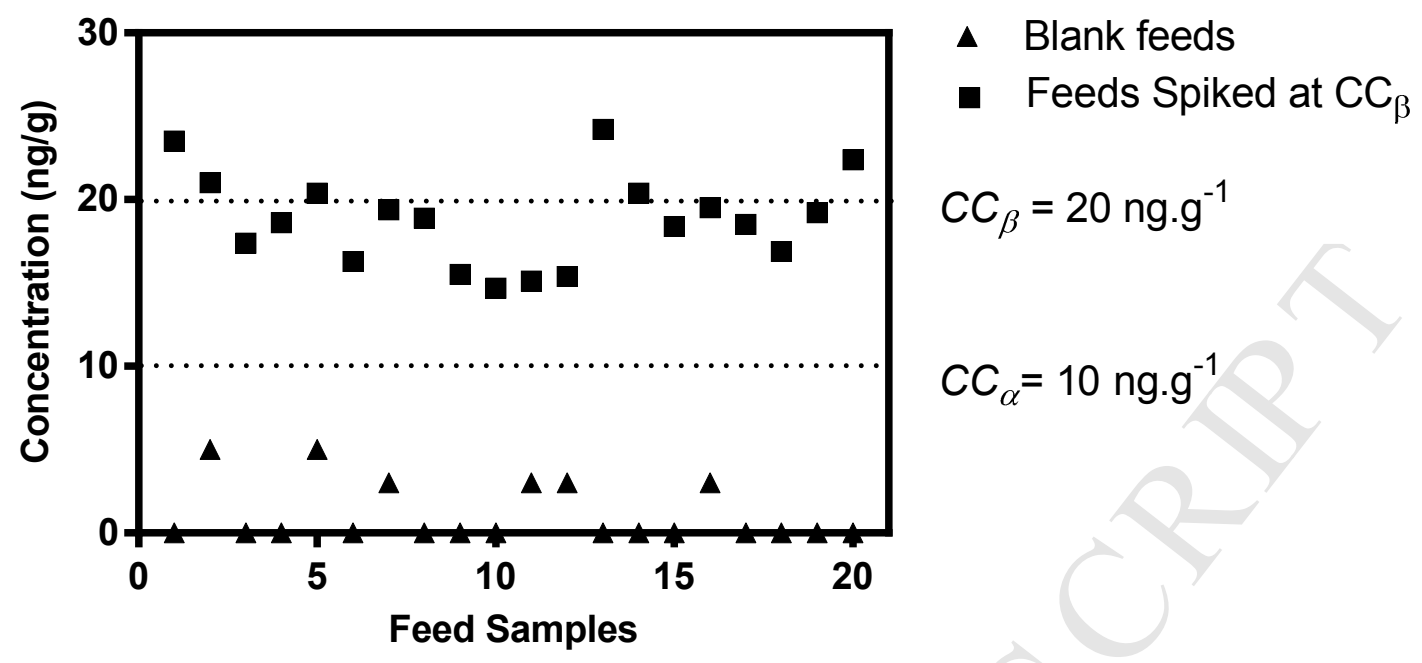




\section{Highlights}

- A quick screenig method for fluoroquinolone in feeds based on ELISA is validated.

- Matrix effect is avoided by only 10 fold dilution of the final feed extract.

- The achieved $C C_{\beta}$ of $20 \mathrm{ng} \cdot \mathrm{g}^{-1}$ for enrofloxacin indicates sufficient sensitivity.

- Good correlation of the method with LC-Fl indicates promising reliability. 